\title{
PENGARUH BIMBINGAN BELAJAR DI LUAR SEKOLAH TERHADAP MINAT UNTUK BERPRESTASI SISWAKELAS VIII MTsN SIDOREJO KABUPATENMADIUN TAHUN PELAJARAN 2014/2015
}

\author{
Pryo Sularso* \\ Wawan Kokotiasa $^{* *}$ \\ David Ardian Paramedica $^{* * *}$
}

\begin{abstract}
Abstrak
$\mathrm{P}$ enelitian ini bertujuan untuk mengetahui pengaruh bimbingan belajar di luar sekolah terhadap minat untuk berprestasi siswa kelas VIII MTsN Sidorejo Kabupaten Madiun tahun pelajaran 2014/2015. Populasi penelitian ini sebanyak 113 siswa. Sampelnya diperoleh kelompok siswa yang hanya mengikuti bimbingan belajar di luar sekolah yaitu sebanyak 28 siswa. Analisis data menggunakan uji normalitas, uji homogenitas, uji linieritas dan uji hipotesis menggunakan regresi sederhana untuk menguji angket. Hasil penelitian menunjukkan bahwa ada pengaruh bimbingan belajar di luar sekolah terhadap minat untuk berprestasi siswa kelas VIII MTsN Sidorejo Kabupaten Madiun tahun pelajaran 2014/2015. Dari $\mathrm{F}_{\text {tabel }}$ dengan db pembilang $=1$ dan $\mathrm{db}$ penyebut $=\mathrm{N}-2=$ $28-2=26$. Pada taraf $\alpha=5 \%$ didapat $F_{\text {tabel }(1,26)}=4,22$. Karena $F_{\text {hit }}>F_{\text {tabel }(1,26 ; 5 \%)}$ yaitu 8,96>4,22, dapat disimpulkan bahwa koefisien arah persamaan regresi cukup berarti pada taraf $\alpha=5 \%$. Hasil uji regresi linier sederhana dan uji $F$ yang menghasilkan $\mathrm{F}$ hitung $>\mathrm{F}$ tabel yaitu $\mathrm{F}$ hitung $(8,958)>\mathrm{F}$ tabel $(4,22)$, maka dapat disimpulkan bahwa secara simultan variable bimbingan belajar di luar sekolah berpengaruh terhadap minat untuk berprestasi siswa kelas VIII MTsN Sidorejo Kabupaten Madiun tahun pelajaran 2014/2015.
\end{abstract}

Kata Kunci: Bimbingan Belajar, Minat untuk Berprestasi

\footnotetext{
* Dosen Prodi PPKn IKIP PGRI Madiun

** Dosen Prodi PPKn IKIP PGRI Madiun

**** Mahasiswa Prodi PPKn IKIP PGRI Madiun
} 
PENDAHULUAN

Pendidikan merupakan salah satu faktor penting untuk menjamin kelangsungan hidup bangsa dan negara. Pendidikan merupakan wahana untuk meningkatkan dan mengembangkan kualitas sumber daya manusia. Tujuan pendidikan nasional bukan sekadar membentuk peserta didik yang pintar dengan memperoleh nilai tinggi di setiap mata pelajaran. Seperti dalam Undang-undang RI No. 20 tahun 2003 tentang Sistem Pendidikan Nasional bahwa Pendidikan nasional berfungsi mengembangkan kemampuan dan membentuk watak serta peradaban bangsa yang bermartabat dalam rangka mencerdaskan kehidupan bangsa, bertujuan untuk berkembangnya potensi peserta didik agar menjadi manusia yang beriman dan bertakwa kepada Tuhan Yang Maha Esa, berakhlak mulia, sehat, berilmu, cakap, kreatif, mandiri, dan menjadi warga negara yang demokratis serta bertanggung jawab. Kenyataannya, masyarakat menganggap sekolah tidak mampu memenuhi kebutuhan belajar siswa. Kegagalan-kegagalan yang dialami siswa dalam belajar tidak selalu disebabkan oleh kebodohan atau rendahnya intelegensi. Seringkali kegagalan itu terjadi karena mereka tidakmendapat layanan bimbingan yang memadai.

Selain belajar di sekolah, anak perlu mengulang pelajarannya di luar sekolah. Dilihat dari nilai ujian, rata-rata nilai ujian siswa masih banyak yang belum memenuhi standar nilai kelulusan. Pada umumnya, prestasi belajar anak akan meningkat dengan adanya perhatian orang tua. Sebagian besar waktu siswa digunakan di lingkungan rumah sehingga orang tua perlu mendampingi mereka untuk belajar di rumah. Sayangnya, tidak sedikit orang tua yang kesulitan mendampingi anaknya belajar di rumah karena kesibukannya, atau pelajaran sang anak belum tentu dipahami orang tuanya.

Alternatif yang dilakukan orang tua untuk mengatasi masalah belajar anak yaitu mengikutkan anaknya bimbingan belajar(Bimbel) dengan mencari guru pembimbing untuk membimbing anak dalam belajar, atau mengadakan les privat yang dilakukan dirumah. Bimbingan 
dapat diartikan sebagai petunjuk, penjelasan cara mengerjakan sesuatu.

Menurut Winkel (dalam Silvia Yula Wardani, 2012: 2) mendefinisikan bimbingan adalah: Proses pemberian bantuan atau pertolongan kepada individu dalam hal memahami diri sendiri, menghubungkan pemahaman tentang dirinya sendiri dengan lingkungannya, memilih, menentukan dan menyusun rencana sesuai dengan konsep dirinya dan tuntutan lingkungan.

Fungsi dari Bimbel secara keseluruhan dapat berfungsi membantu dan menunjang usahausaha kearah kemajuan, kesejahteraan dan tercapainya tujuan pendidikan bagi sekolah maupun bagi anak didik terutama dalam proses belajar mengajar didalam pendidikan dan pengajaran yang dijalankan. Seperti dikemukakan oleh Syamsu Yusuf dan Juntika Nurihsan(2010: 16) bahwa salah satu fungsi bimbingan adalah sebagai pemahaman, yaitu "membantu peserta didik(siswa) agar memiliki pemahaman terhadap dirinya(potensinya) dan lingkunganya. Individu diharapkan mampu mengembangkan potensi dirinya secara optimal dan menyesuaikan diri terhadap lingkunganya".

Les privat yaitu bantuan yang diberikan pembimbing kepada siswa dalam kesulitan belajar yang dilakukan secara pribadi. Beberapa keistimewaan les privat yaitu, anak lebih terpantau belajarnya oleh orang tua karena kegiatan belajarnya di rumah, anak akan lebih terbuka berkaitan dengan materi pelajaran yang dianggapnya sulit, anak akan lebih konsentrasi belajarnya karena tidak ada yang mengganggu dan anak juga berkesempatan mengulang kembali pelajaran sekolah untuk lebih memahami lagi. Apakah bimbingan belajar diluar sekolah dapat membantu siswa dalam kesulitan belajar?Hal inilah yang mendasari dilakukan penelitian tersebut.

\section{METODE PENELITIAN}

Populasi penelitian ini sebanyak 113 siswa. Sampelnya diperoleh kelompok siswa yang hanya mengikuti bimbingan belajar di luar sekolah yaitu sebanyak 28 siswa.Analisis data menggunakan uji 
normalitas, uji homogenitas, uji linieritas dan uji hipotesis menggunakan regresi sederhana untuk menguji angket.

1. Uji Normalitas
a. Menentukan $\mathrm{H}_{0}$ dan $\mathrm{H}_{\mathrm{a}}$
b. Menentukan
taraf signifikansi, yaitu $\alpha=0,05$
c. Menentukan statistik uji yang digunakan:

$$
L=\operatorname{Maks}\left|F\left(z_{i}\right)-S\left(z_{i}\right)\right|
$$

Keterangan:

$\mathrm{Z}_{\mathrm{i}}=\frac{x_{i}-x}{s}$

$\mathrm{F}\left(\mathrm{z}_{\mathrm{i}}\right)=$ nilai $\mathrm{z}_{\mathrm{i}}$ dalam tabel

$\mathrm{S}\left(\mathrm{Z}_{\mathrm{i}}\right)=\frac{1}{n}, n=$ ukuran sampel

d. Menghitung statistik uji berdasarkan data observasi yang diperoleh dari sampel

e. Menentukan nilai kritik dan daerah kritik

Nilai kritik $=L_{(\alpha ; n)}$ dan $\mathrm{DK}=$

$$
L \mid L>L_{\alpha ; n}
$$

f. Menentukan keputusan uji

Jika $L_{o b s}<D K$, maka $\mathrm{H}_{0}$ ditolak

Jika $L_{o b s}>D K$, maka $\mathrm{H}_{0}$ diterima

g. Menyimpulkan berdasarkan keputusan uji yang diperoleh

2. Uji Homogenitas

$$
F=\frac{\text { VarianTertinggi }}{\text { VarianTerendah }}
$$

Varians dapat dicari dengan rumus: $s^{2}=\frac{\sum\left(x_{i}-x\right)^{2}}{(n-1)}$

Keterangan:

$\mathrm{s}=$ varians

$x_{i}=$ total nilai sampel

$x=$ mean

$\mathrm{n}=$ jumlah sampel

3. Uji Linieritas Regresi

a. Menyusun tabel kelompok data variabel $\mathrm{X}_{1}$ dan $\mathrm{Y}$.

b. Menghitung jumlah kuadrat regresi (a)

$J K_{\text {reg } a}=\frac{\sum Y^{2}}{N}$

c. Menghitung jumlah kuadrat regresi $b \mid a$

$$
\begin{gathered}
J K_{\text {reg }(b / a)}=b\left(\sum X Y-\frac{\sum x \cdot \sum y}{N}\right) \\
b=\frac{N \cdot \sum X Y-\sum x \cdot \sum y}{N \cdot \sum x^{2}-\left(\sum x\right)^{2}}
\end{gathered}
$$

d. Menghitung jumlah kuadrat residu

$$
\begin{aligned}
J K_{\text {res }}=\quad Y^{2} & -J K_{R e g(b / a)} \\
& -J K_{R e g(b)}
\end{aligned}
$$

e. Menghitung rata-rata jumlah kuadrat regresi a $R J K_{\text {reg } a}=J K_{\text {reg }(a)}$

f. Menghitung rata-rata jumlah kuadrat regresi b/a $R J K_{\operatorname{Reg}(b / a)}=\mathrm{JK}_{\operatorname{Reg}(\mathrm{b} / \mathrm{a})}$

g. Menghitung rata-rata jumlah kuadrat residu

$$
R J K_{\text {res }}=\frac{J K_{\text {res }}}{n-2}
$$


h. Menghitung jumlah kuadrat error

$$
J K_{E}=Y_{k}^{2}-\frac{Y^{2}}{2}
$$

i. Menghitung jumlah kuadrat tuna cocok

$J K_{T C}=J \boldsymbol{K}_{\text {Res }}-\boldsymbol{J} \boldsymbol{K}_{\boldsymbol{E}}$

j. Menghitung rata-rata jumlah

kuadrat tuna cocok

$R J K_{T C}=\frac{J K_{T C}}{k-2}$

k. Menghitung rata-rata jumlah

kuadrat error

$$
R J K_{E}=\frac{J K_{E}}{n-k}
$$

1. Mencari nilai uji $\mathrm{F}$

$$
F=\frac{R J K_{T C}}{R J K_{E}}
$$

m. Membandingkan nilai $F_{\text {hitung }}$ dengan $\mathrm{F}_{\text {tabel }}$.

n. Ha diterima apabila nilai $\mathrm{F}_{\text {hitung }}<\mathrm{F}_{\text {tabel, }}$ artinya data berpola linier.

Ho diterima apabila nilai $F_{\text {hitung }}>$ $F_{\text {tabel, }}$ artinya data berpola tidak linier

4. Uji Hipotesis

$\mathrm{Y}=\mathrm{a}+\mathrm{bX}$

Keterangan :

Y : Kriterium

X : Prediktor

a : Intersep (konstanta regresi)

b : Koefisien regresi atau slove, gradien, atau kemiringan garis
Untuk

menarik

kesimpulan atau uji signifikansi dari persamaan regresi dengan cara mencari nilai $F$ regresi dengan rumus sebagai berikut :

$$
F=\frac{R k_{r e g}}{R k_{r e s}}
$$

Keterangan :

$$
\begin{array}{ll}
\mathrm{F} & : \text { harga F regresi } \\
R k_{\text {reg }} & : \text { kuadrat regresi } \\
R k_{\text {res }} & : \text { koefisien korelasi }
\end{array}
$$

\section{HASIL DAN PEMBAHASAN}

1. Uji Normalitas

Semua uji statistik mengenai rataan mempunyai persyaratan bahwa sampel harus diambil dari populasi normal. Oleh karena itu, data yang diambil harus diuji dengan uji normalitas untuk mengetahui sampel yang diambil berasal dari populasi yang berdistribusi normal. Hasil uji normalitas disajikan pada tabel berikut:

Tabel 1. Hasil uji normalitas

\begin{tabular}{|c|c|c|c|}
\hline Variabel & $\mathrm{L}_{\text {obs }}$ & $\mathrm{L}_{\text {tabel }}$ & $\begin{array}{c}\text { Keputusan } \\
\mathrm{Uji}\end{array}$ \\
\hline $\begin{array}{c}\text { Bimbingan } \\
\text { Belajar di } \\
\text { Luar } \\
\text { Sekolah }\end{array}$ & 0.0993 & $\begin{array}{c}\mathrm{L}_{0.05 ; 28}= \\
0.1730\end{array}$ & $\begin{array}{c}\mathrm{H}_{0} \\
\text { diterima }\end{array}$ \\
\hline $\begin{array}{c}\text { Minat untuk } \\
\text { Berprestasi }\end{array}$ & 0.1209 & $\begin{array}{c}\mathrm{L}_{0.05 ; 28}= \\
0.1730\end{array}$ & $\begin{array}{c}\mathrm{H}_{0} \\
\text { diterima }\end{array}$ \\
\hline
\end{tabular}


Dari tabel di atas, dapat dilihat bahwa pada kelas variabel bimbingan belajar di luar sekolah $\mathrm{L}_{\text {obs }}=0,0993<\mathrm{L}_{\text {tabel }}=0,1730$, artinya $\mathrm{L}_{\mathrm{obs}}$ tidak terletak pada daerah kritik sehingga $\mathrm{H}_{0}$ diterima. Berarti sampel pada variabel bimbingan belajar di luar sekolah tersebut berasal dari populasi yang berdistribusi normal.

Variabel minat untuk berprestasi $\mathrm{L}_{\mathrm{obs}}=0,1209<\mathrm{L}_{\text {tabel }}=$ 0,1367, artinya $\mathrm{L}_{\mathrm{obs}}$ tidak terletak pada daerah kritik sehingga $\mathrm{H}_{0}$ diterima. Berarti pada data minat untuk berprestasi tersebut berasal dari populasi yang berdistribusi normal.

2. Uji Homogenitas

Uji homogenitas digunakan untuk mengetahui kedua kelompok memiliki tingkat varian data yang sama atau tidak. Hasil uji homogenitas disajikan pada tabel berikut:

Tabel 2. Hasil uji homogenitas

\begin{tabular}{|c|c|c|c|}
\hline $\mathrm{F}_{\text {hitung }}$ & $\mathrm{F}_{\text {tabel }}$ & Kriteria & $\begin{array}{c}\text { Keputusan } \\
\text { Uji }\end{array}$ \\
\hline 1.18 & $\begin{array}{c}\mathrm{F}_{0.05 ; 28}=1 . \\
93\end{array}$ & $\mathrm{~F}_{\text {hitung }} \leq \mathrm{F}_{\text {tabel }}$ & $\mathrm{H}_{0}$ diterima \\
\hline
\end{tabular}

Dari tabel di atas dapat dilihat bahwa hasil analisis data uji homogenitas diperoleh $F_{\text {hitung }}$ $=1.18$. Dan $F_{\text {tabel }}=1.93$. Dengan kriteria pengujian $\mathrm{H}_{0}=\mathrm{F}_{\text {hitung }} \leq$ $\mathrm{F}_{\text {tabel }} ; 1.18 \leq 1.93$. Hal ini berarti $\mathrm{H}_{0}$ diterima. Dapat disimpulkan bahwa sampel berasal dari populasi yang memiliki varians homogen.

3. Uji Linieritas

Setelah diketahui data normal dan homogen, selanjutnya dihitung linieritas datanya. Ringkasan hasil uji linieritas dapat dituangkan dalam tabel3 sebagai berikut.

Tabel 3. Hasil Uji Linieritas

\begin{tabular}{|c|c|c|c|c|c|}
\hline Varians & J $\quad \mathrm{K}$ & $\mathrm{Db}$ & $\mathrm{R} \mathrm{J} \mathrm{K}$ & $\mathrm{F}_{\text {hit }}$ & $\mathrm{F}_{\mathrm{tab}}(5 \%)$ \\
\hline Tota 1 & 77351 & 28 & & & \\
\hline Regresi $_{(\mathrm{a})}$ & 77070,036 & 1 & 77070,036 & & \\
\hline Regresi $_{(b / a)}$ & 118,1256 & 1 & 118,1256 & 8,96 & 4.22 \\
\hline$S$ i s a & 342,8387 & 26 & 13,1861 & & \\
\hline Eror/Galat & 181,1667 & 13 & 13,9359 & & \\
\hline T. Cocok & 161,6720 & 13 & 12,4363 & 0,89 & 2.60 \\
\hline
\end{tabular}

Berdasarkan tabel di atas, dapat dilihat bahwa nilai $F_{\text {hitung }}$ $=0.89<2.60=\mathrm{F}_{\text {tabel }}$ dengan taraf signifikansi sebesar 5\%. Artinya data variabel bimbingan belajar di luar sekolah terhadap minat untuk berprestasi siswa berpola linier. 
4. Uji Hipotesis

Teknik korelasi digunakan untuk mencari besarnya hubungan antar variabel. Nilai koefisien korelasi sebesar 0.5062 dan indeks determinasi sebesar 0.2565. Artinya, bahwa korelasi antara variabel bimbingan belajar di luar sekolah terhadap minat untuk berprestasi memiliki korelasi yang cukup.Dari sinilah dapat dilakukan uji hipotesis untuk regresi.

Analisis regresi digunakan untuk menelaah pola hubungan yang modelnya belum diketahui dengan sempurna, atau untuk mengetahui variasi dari beberapa variabel independen yang mempengaruhi variabel dependen dalam satu fenomena yang kompleks.

Dari $\mathrm{F}_{\text {tabel }}$ dengan $\mathrm{db}$ pembilang $=1$ dan $\mathrm{db}$ penyebut $=$ $\mathrm{N}-2=28-2=26$. Pada taraf $\alpha=$ $5 \%$ didapat $\mathrm{F}_{\text {tabel }(1,26)}=4,22$. Karena $\quad \mathrm{F}_{\text {hit }}>\mathrm{F}_{\text {tabel(1,26; } 5 \%)}$ yaitu $8,96>4,22$. Maka dapat disimpulkan bahwa koefisien arah persamaan regresi cukup berarti pada taraf $\alpha=5 \%$. Berdasarkan nilai hitung yang diperoleh, diketahui nilai hitung $\mathrm{F}_{\text {hitung }}=8.958>4.22=\mathrm{F}_{\text {tabel }}$. Jadi, koefisien regresi signifikan dan disimpulkan bimbingan belajar di luar sekolah berpengaruh terhadap minat untuk berprestasi.

\section{KESIMPULAN}

Berdasarkan hasil penelitian yang dilakukan, dapat ditarik kesimpulan bahwa terdapat pengaruh yang positif dan signifikan dari pengaruh bimbingan belajar di luar sekolah terhadap minat untuk berprestasi siswa kelas VIII MTsN Sidorejo Kabupaten Madiuntahun pelajaran 2014/2015.Pengaruh tersebut dapat dilihat dari hasil angket siswa yang mengikuti bimbingan belajar di luar sekolah kelas VIII MTsN Sidorejo Kabupaten Madiun.Hasil tersebut dianalisis dengan uji linier dan uji F. Jika $F_{\text {hitung }}>F_{\text {tabel}}$, hipotesis diterima, yaitu ada pengaruh bimbingan belajar di luar sekolah terhadap minat untuk berprestasi siswa kelas VIII MTsN Sidorejo Kabupaten Madiun tahun pelajaran 2014/2015.Jika $\quad F_{\text {hitung }}<\quad F_{\text {tabel }}$, hipotesis ditolak, yaity tidak ada 
pengaruh bimbingan belajar di luar sekolah terhadap minat untuk berprestasi siswa kelas VIII MTsN Sidorejo Kabupaten Madiun tahun pelajaran 2014/2015.Hal ini ditunjukkan pada hasil uji regresi linier sederhana dan uji $F$ yang menghasilkan $\mathrm{F}$ hitung $>\mathrm{F}$ tabel yaitu $\mathrm{F}$ hitung $(8,958)>\mathrm{F}$ tabel $(4,22)$. Jadi, dapat disimpulkan bahwa secara simultan variabelbimbingan belajar di luar sekolah berpengaruh terhadap minat untuk berprestasi siswa kelas VIII MTsN Sidorejo Kabupaten Madiun tahun pelajaran 2014/2015. 


\section{DAFATAR PUSTAKA}

Achmad Juntika Nurihsan dan Akur Sudianto. 2005. Manajemen bimbingan Dan Konseling Di SMP. Jakarta: PT Grasindo Anggota Ikapi.

Budiyono. 2009. Statistika untuk penelitian. Surakarta : Sebelas Maret University press.

Dewa Ketut Sukardi dan Desak Made

Sumiati.1990.Bimbingan

Penyuluhan Di Sekolah. Bandung: Satu Nusa.

Djali. 2007. Psikologi Pendidikan. Jakarta: PT Bumi Aksara.

Hamdani. 2011. Strategi Belajar Mengajar. Bandung : Pustaka Setia.

Hamid Darmadi. 2010.Kemampuan Dasar Mengajar. Bandung: ALFABETA.

Jeanne Ellis Ormrod. 2008. Psikologi Pendidikan. Jakarta : Erlangga.

Muhibbin Syah. 2009. Psikologi Belajar. Jakarta: PT Rajagrafindo Persada.

Prayitno dan Erman Amti. 2004. Dasar-Dasar Bimbingan Dan Konseling. Jakarta: PT Rineka Cipta.

Oemar Hamalik. 2009. Psikologi Belajar \& Mengajar. Bandung : Sinar Baru Algensindo.

Reni Akbar Hawadi. 2006. Akselerasi: $\quad A-Z$ Informasi
Program percepatan Belajar dan Anak Berbakat Intelektual. Jakarta : Grasindo Anggota Ikapi.

Sambas Ali Muhidin dan Maman Abdurahman. 2009. Analisis Korelasi, Regresi, dan Jalur Dalam Penelitian. Bandung: CV Pustaka Setia

Silvia Yula Wardani. 2012. Diktat Mata Kuliah Pengantar Bimbingan. Madiun: IKIP PGRI Madiun.

Slameto. 2010. Belajar \& FaktorFaktor yang Mempengaruhi. Jakarta: Rineka Cipta.

Sudarwan Danim. 2010. Perkembangan Peserta Didik. Bandung: ALFABETA.

Sugiyono. 2012. Metode Penelitian Kuantitatif, Kualitatif dan $R \& D$. Bandung:Alfabeta.

. 2013. Statistik Untuk Penelitian. Bandung: Alfabeta.

Suharsimi Arikunto. 2006. Prosedur Penelitian Suatu Pendekatan Praktik. Jakarta: PT. Rineka Cipta.

. 2013. Manajemen Penelitian. Jakarta: PT. Rineka Cipta.

Syaiful Bahri Djamarah. 2008. Psikologi Pendidikan. Jakarta: PT Rineka Cipta.

- 2012. Prestasi Belajar Dan kompetensi Guru.Surabaya: Usaha Nasional.

Syamsu Yusuf dan Juantika Nurihsan. 2010. Landasan Bimbingan \& Konseling. 
Bandung: PT Remaja

Rosdakarya.

Tulus Tu'u. 2004. Peran Disiplin pada Perilaku dan Prestasi Siswa. Jakarta: Grasindo.

Tulus Winarsunu. 2010. Statistik Dalam Penelitian Psikologi \& Pendidikan. Malang: UMM Press.

Tyas Martika Anggriyana dkk. 2013. Diktat

Psikologi Perkembangan Dewasa Dan Lansia.Madiun: IKIP PGRI Madiun. 